\title{
NASDAL: Prices hold up
}

Goodwill prices have held up throughout a turbulent 2020, according to the latest results published from the NASDAL

(National Association of Specialist Dental Accountants and Lawyers) Goodwill Survey statistics.

In the period from 1 April to 30

September 2020 based on deals done (i.e. practices bought or sold by NASDAL members' clients in the period), goodwill as a percentage of fee income in the period across all types of practice averaged $141 \%$ of gross fees - only down from $159 \%$ from the quarter to January 2020 - the last preCOVID-19 quarter.

NHS Goodwill values were higher when compared to the previous quarter with 191\% of gross fees across the six months to $166 \%$ of gross fees last time. Private goodwill values fell back to $114 \%$ of gross fees from $143 \%$ of gross last time. The big fallers were mixed practices - falling from $188 \%$ of gross fees in the quarter ending January 2020 to just $110 \%$ of gross fees this time.

Alan Suggett, specialist dental accountant and partner in UNW LLP who compiles the goodwill survey, said: 'I have to say that both the level of deal activity and the pricing levels have surprised me. I was expecting to see a big drop in the number of practice sales coupled with a sharp fall in prices. In NASDAL members' experience, there have been only limited price reductions and the corporates haven't used COVID-19 as an opportunity to negotiate lower deal values. It certainly does show that the UK dental practice sales market is not the nightmare that some commentators have suggested!
'We do know that many lenders are coming up with an increasing array of hoops for borrowers to go through - which puts cash buyers in a stronger position.

'We decided not to include valuations during this six month period as the amount of data was lower than usual, and valuations are invariably subjective, which is unhelpful during this period of uncertainty'

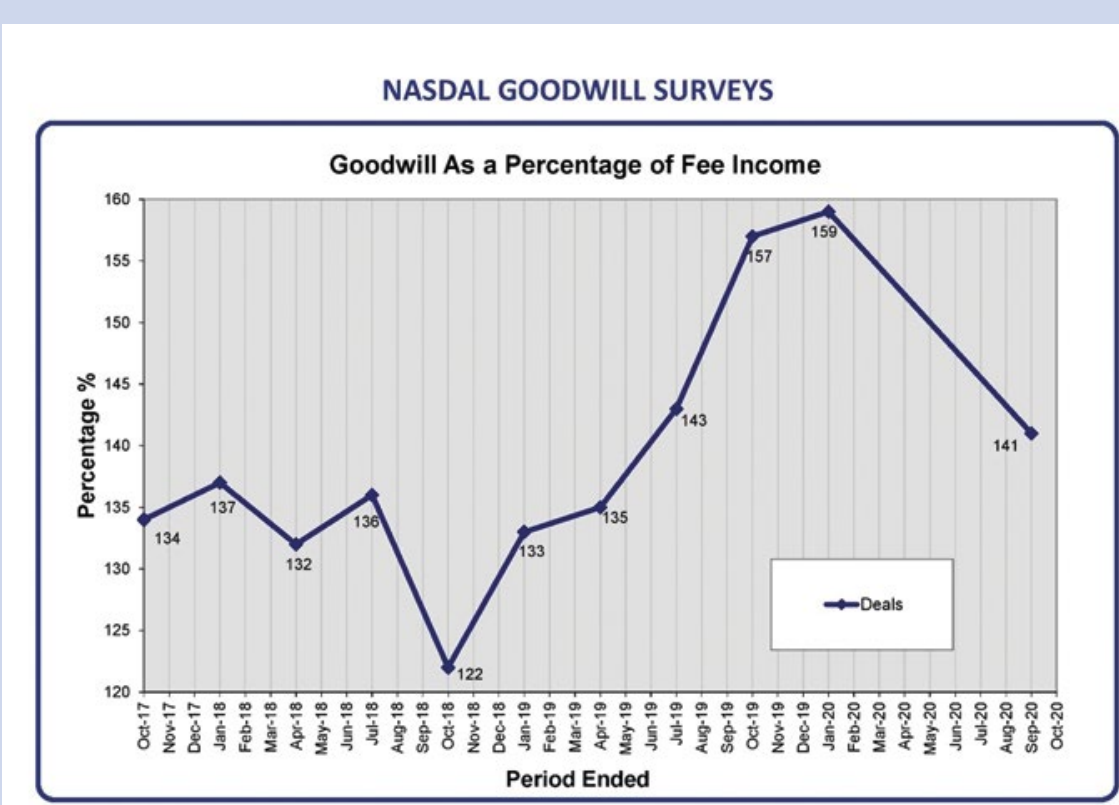

\section{Dentists greet leadership from Welsh Government on restoring access}

The British Dental Association has welcomed the Welsh Government's commitment to offer capital funding to help dental practices secure new equipment to expand patient numbers.

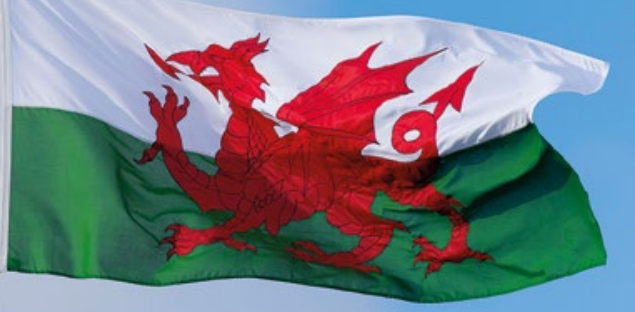

Health Minister Vaughan Gething MS has agreed a funding package of $£ 450,000$ in 2020-21 to support dental practices in improving surgery ventilation. The BDA had appealed to all four UK governments to provide support, and has welcomed the Welsh Government's leadership on the issue.

Nearly $80 \%$ of practices in Wales are running at under half their pre-pandemic capacity. Fallow time is currently the number one barrier practices face to increasing patient numbers. New ventilation systems can help practices slash their fallow time to a matter of minutes, offering hope of significant expansion in patient access.

The package will enable many practices to invest in new kit, which the majority of practices reported they were unable to fund independently. The BDA is now seeking detail on the mechanics of the fund.

Dr Katrina Clarke, Chair of British Dental Association's Welsh Council said: 'The Health Minister has shown real leadership in getting dentistry back up and running.

'The rules dentists are obliged to work under have left millions across the UK unable to secure an appointment. This pledge of capital funding will translate into better access for families across Wales.

'From decay to oral cancer every lost appointment represents a missed opportunity to nip problems in the bud. The Welsh Government has put patients first. We look to the authorities in Westminster, Belfast and Edinburgh to do the same. 